\title{
Healthy Children Arizona: Early Intervention for Prevention
}

\author{
Sabrina Plattner ${ }^{1}$, Gayle McCartney², Cynthia Thomson'1,2,3, Andrea Balderama ${ }^{3}$, \\ David S. Alberts ${ }^{1,2,3}$, Janet A. Foote ${ }^{2,3}$ \\ ${ }^{1}$ Department of Nutritional Sciences, College of Agriculture and Life Sciences, University of Arizona, Tucson, AZ, \\ USA \\ ${ }^{2}$ The University of Arizona Cancer Center, Tucson, AZ, USA \\ ${ }^{3} \mathrm{Mel}$ and Enid Zuckerman College of Public Health, University of Arizona, Tucson, AZ, USA \\ Email: jfoote@email.arizona.edu
}

Received 28 June 2014; revised 31 July 2014; accepted 26 August 2014

Copyright @ 2014 by authors and Scientific Research Publishing Inc.

This work is licensed under the Creative Commons Attribution International License (CC BY).

http://creativecommons.org/licenses/by/4.0/

(c) (i) Open Access

\begin{abstract}
The Healthy Children Arizona (HCA) program was developed to promote early, positive exposure to cancer-preventive diet, physical activity and sun safety behaviors. Five lessons delivered weekly were evaluated by classroom teachers while pre- and post-curriculum surveys examined increases in students' understanding of concepts and self-reported behavior. The first and second graders and their teachers in ethnically diverse elementary schools (including Title 1) in Tucson and Phoenix, Arizona participated in the curriculum assessment. All 5 interactive lessons were highly rated by teachers in qualitative assessments. Aggregated analyses of pre- $(n=582)$ and post- $(n=588)$ comparison tests indicated that the HCA curriculum significantly increased students' knowledge of each of six measured concepts $(p<0.0001)$, although correct choice of musclebuilding foods $(25 \%)$, whole grain items $(78 \%)$ and target time for daily exercise $(61 \%)$ were lower than desired. Mean self-reported fruit and vegetable servings eaten in the previous day increased from $3.1 \pm 1.8$ to $3.8 \pm 1.6(p<0.0001)$. The HCA curriculum significantly improved cancer prevention knowledge among primary school children.
\end{abstract}

\section{Keywords}

Curriculum, Healthy Eating, Children, Cancer Prevention, Sun Safety

\section{Introduction}

In 2005, the University of Arizona College of Agriculture and Life Sciences in partnership with the Cancer Center set out to develop an interactive program to educate primary age school children about the importance of 
healthful dietary choices, physical activity and sun safety for cancer prevention. This program called Healthy Children Arizona (HCA), has reached approximately 20,000 students in the metropolitan Tucson and Phoenix since 2006. The overall goal is to establish healthy cancer preventive behaviors in young children that will become habitual resulting in healthier adult behaviors and potentially lower cancer incidence.

Cancer is an adult disease for which early lifestyle behaviors influence adult disease incidence. This is particularly true for obesity-associated cancers (e.g. breast, colorectal, bladder, and endometrial) [1]. Overweight/obese children are at greater risk of demonstrating excess body weight/body mass index in adulthood and thus have greater potential for experiencing a cancer diagnosis in adulthood [2]. Further, it is well established that obesity and obesity-related disease are increasing at a staggering rate among US children [3]-[6], including Arizona where the increase in obesity incidence led all states between 2003 and 2007 [6]. Importantly, the proportion of obese children in Arizona is $10 \%$ to $16 \%$ higher among Hispanics and Native Americans [5]-[7]. The most compelling of modifiable risk factors for cancer is diet and physical activity [1]. Earlier adoption of healthy behaviors has been suggested to influence decision making related to health behaviors later in life [8] making young children a prime target for early intervention and education to reduce adult cancer risk.

A critical step in curriculum development is ensuring that the lessons are accessible and relevant to the students and that students demonstrate an increase in understanding following implementation. Using a two-step evaluation approach, both the teachers and the students provided feedback to determine the effectiveness of the HCA curriculum.

\section{Methods}

\subsection{Healthy Children Arizona Curriculum}

The Healthy Children Arizona curriculum was designed by health educators, dietitians and medical professionals in partnership with the Supplemental Nutrition Assistance Program Educational (SNAP-Ed) faculty at the University and the Cancer Center. The curriculum includes three dietary lessons (Rainbow on My Plate, Food Group Detectives, and Healthy Choices), one physical activity lesson (Get Moving) and a sun awareness lesson (Sun Safety) all of which meet state educational standards. Curriculum includes educational objectives, applicable state standards teaching materials and learning activities for implementation in the classroom. The curriculum is generally delivered as a single 45-minute lesson per week over five consecutive weeks. Delivery is led by a health educator or dietetics professional trained in curriculum deliverance and with demonstrated experience teaching the target age group.

The HCA program was developed using Social Cognitive Theory (SCT) and as such takes advantage of the dynamic connection between environmental factors, personal factors and human behavior that influences health behavior [9] [10]. Healthy Children Arizona (HCA) learning activities are designed to enhance self-efficacy, goal setting and the positive outcomes of healthful behavior (outcome expectancies) each of which are central constructs of SCT [10]. HCA uses these concepts as building blocks, incorporating encouraging role models in the classroom, step-by-step practice opportunities for success in building skills, and positive reinforcement to create a "norm" of making healthy choices [9]-[11].

\subsection{Participants}

First and second grade level elementary students (age five to eight years) and classroom teachers in the Tucson and Phoenix metropolitan areas participated in this evaluation survey, including economically disadvantaged schools (Title One schools). The HCA Program built a relationship with schools through the Director of Health and Wellness or similar leadership role at the district level as well as direct meetings with teachers and principals. Since the 2006 program initiation, approximately 22,000 students in more than 400 classrooms have participated. In classes which were receiving the instruction, the teachers were asked if they were voluntarily willing to complete the teacher evaluation surveys and have their students complete the picture-based knowledge assessments. This evaluation represents 312 teacher and more than 580 student responses for each of the pre- and post-learning survey administrations.

\subsection{Curriculum Implementation and Evaluation Survey}

After an initial orientation meeting during which curriculum materials were shared, district and/or school offi- 
cials reviewed materials with necessary approval personnel before curriculum implementation. Initially a process evaluation was developed to acquire teacher feedback regarding the curriculum, and subsequently a separate brief knowledge survey was developed to assess learning among the young students. Briefly, the student pictorial survey included questions related to diet, physical activity and sun safety behaviors consistent with content of the curriculum lessons. The HCA pre- and post-curriculum survey included a brief indicator of change in fruit and vegetable intake by asking students to circle the number of fruits and vegetables eaten the previous day. Surveys were administered in the classroom just prior to the first lesson and again at the end of the last lesson (Figure 1). Each question was orally recited and students were given as much time as needed to provide a response on the survey page. Survey responses were not matched for individuals and class attendance likely varied between pre and post tests on an individual level; analysis of pre and post-curriculum responses was determined from aggregate data.

Teachers were given five evaluation surveys to complete; one for each of the five lessons. Each lesson included an evaluation of the strengths and weakness of the HCA program using a 5-point Likert-type scale for responses ranging from "poor" to "excellent" for quality of content, format/approach and visual aids and separate a scale ranging from "not at all" to "extremely well" for nine other evaluation factors. Teachers also provided an evaluation of effectiveness on a 5-point scale with 1 being "not effective" and 5 being "highly effective" (Figure 1).

Surveys were designed so that each lesson evaluation survey included a consistent set of questions and scoring scale/indicators. Surveys were administered in all eligible schools and designated classrooms between February and May, 2010. The surveys did not include any personal identifying information and therefore was deemed as exempt from IRB review at the university. The study population was characterized in terms of grade and age was provided by the teacher respondents and by the HCA administrators.

\subsection{Statistical Analysis}

Mean and SD and/or frequency were used to describe teacher evaluation responses, chi-square analyses were used to examine differences in distribution proportions and student's t-test was used to determine group differences between pre and post-tests. A p value of 0.05 or less was considered significant. All statistical analysis was completed using SAS version $9.1^{1}$ and used aggregate data by time point.

\section{Results}

The HCA program was evaluated on two levels. A process evaluation of the materials acquired feedback from the early elementary school teachers and a brief pre-test, post-test assessment determined the change in knowledge and self-reported fruit and vegetable intake among the children. Table 1 provides a summary of response rates of the curriculum evaluation from the teachers. Response rates for the 312 teachers contacted varied from $65 \%$ to $81 \%$ by lesson for the five lessons. The mean responses to ratings of nine attributes indicated that the proportion of teachers rating the lessons as performing very or extremely well ranged from $77 \%$ to $90 \%$ across the five curriculum foci.

Table 2 describes the overall evaluation scores. Of importance, the mean response to lesson 1 indicated that the lesson was poorly linked to previously learned skills. Teachers rating of the lessons in relation to adaption to students' cultural differences was favorable, although scoring on 2 of the diet lessons, "Rainbow on my plate" and "Food group detectives" were rated the lowest on adapting to the students' cultural differences. Teacher rating of the effectiveness of curriculum student activities showed ratings were high (range: 4.49 to 4.87 on the 5-point scale). The fruit and vegetable song activity had the most variability in effectiveness rating (range: 2.0 to 5.0; mean $4.62+0.73$ ). All mean ratings were above 4.5 with the mean ratings for four activities above 4.8: 1) sun cowboy puppet show, 2) activity break, 3) physical Edna puppet show, and 4) five or more rainbow way slogan.

More than 580 first and second grade students completed the survey assessments for both the pre and post curriculum evaluation. For the pre assessment $73.5 \%$ were enrolled in 1 st grade $(n=432)$ and $26.5 \%(n=156)$ were in 2nd grade; for the post-curriculum evaluation, $82.5 \%(n=478)$ were 1 st grade students and $17.9 \%$ were 2 nd grade students.

As indicated by the summary in Table 3, overall the five lessons HCA curriculum significantly increased understanding of healthy cancer prevention behaviors with the increase in the proportion of students selecting the

\footnotetext{
${ }^{1}$ The analysis for this paper was generated using SAS software, version 9.1. Copyright ${ }^{\circ}$ [2002] SAS Institute Inc. SAS and all other SAS Institute Inc. product or service names are registered trademarks or trademarks of SAS Institute Inc., Cary, NC, USA.
} 


\section{Student Survey}

Grade

Circle your answer

1. How many fruits and vegetables did you eat yesterday?
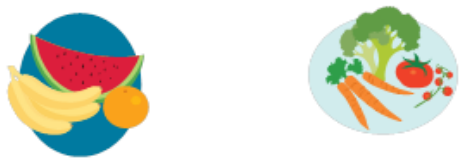

0

1

2

34

2. Which food is a bone-building food?
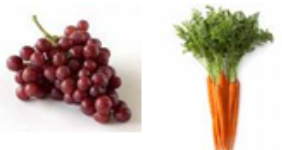

grapes

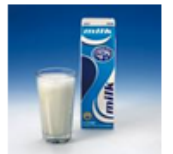

milk

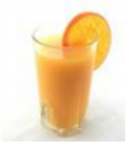

fruit juice

3. Which food helps your brain and builds muscles?

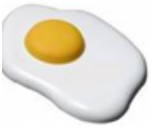

egg

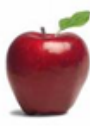

apple

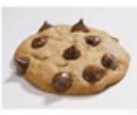

cookie

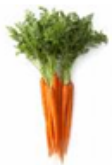

carrot

\section{Teacher Evaluation}

Healthy Children Arizona: Lesson Evaluation Form

Lesson: Rainbow on Your Plate

Learning Objectives:

(a) Identify reasons for eating at least 5 fruits \& vegetable servings/day

(b) Identify various foods by color \& key nutrients

(c) [ $1^{\text {tt }}$ grade and beyond] Name the 6 food groups \& practicecl assifying foods into the appropriategroups.

("nutrient defined as what is in the food that makes it good for us).

Please indicate the response that best fits your assessment: provide additional comments if appropriate.

1. How well do you feel the lesson objectives were met?

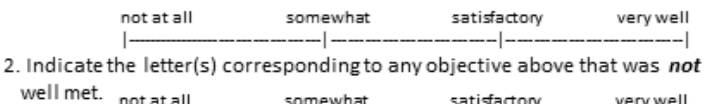

well met. not at all somewhat satisfactory verywell

|

3. How age-appropriate are the learning objectives?

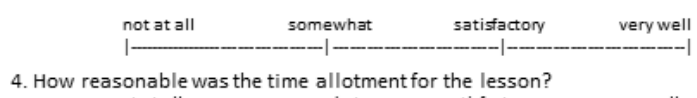

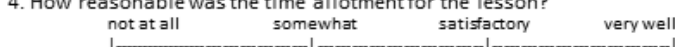

5. How sufficient were background material and resources provided for you? not at all somewhat $\quad$ satisfactory $\quad$ very well

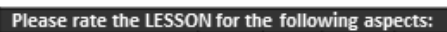

\begin{tabular}{|l|l|l|l|l|}
\hline \multicolumn{1}{|c|}{ Please rate the LESSON for the following aspects: } \\
\hline & Poor & Fair & Good & Excellent \\
\hline Quality of content & & & & \\
\hline Format/ approach & & & & \\
\hline Visual aids & & & & \\
\hline
\end{tabular}

Please check the box corresponding to how well you felt the lesson:

\begin{tabular}{|l|l|l|l|l|l|}
\hline & not at all & somewhat & satisfactory & very well \\
\hline Link to previously learned skills? & & & & \\
\hline Reflected lesson objectives? & & & & \\
\hline Promotes healthy behaviors \& practices? & & & & \\
\hline Applies for student feedback \& guidance? & & & & \\
\hline
\end{tabular}

Figure 1. Provides examples of the evaluation instruments. The first page of the student survey and the teacher evaluation form for lesson one is provided above. The teacher evaluations included a common core of elements to evaluate the specific HCA lesson along with questions that were specific to the activities of the particular lesson.

Table 1. The following table summarizes the Healthy Children Arizona teacher evaluation response rates for each lesson, by city and overall.

\begin{tabular}{|c|c|c|c|c|c|c|c|c|c|}
\hline \multirow{3}{*}{ Lesson } & \multicolumn{9}{|c|}{ Teacher Evaluation Responses } \\
\hline & \multicolumn{3}{|c|}{ Tucson } & \multicolumn{3}{|c|}{ Phoenix } & \multicolumn{3}{|c|}{ Overall } \\
\hline & Returned & Given & $\begin{array}{l}\text { Response } \\
\text { Rate }\end{array}$ & Returned & $\begin{array}{c}\text { Given } \\
\text { Response }\end{array}$ & $\begin{array}{l}\text { Response } \\
\text { Rate }\end{array}$ & Returned & Given & $\begin{array}{c}\text { Response } \\
\text { Rate }\end{array}$ \\
\hline 1. Rainbow on my plate & 26 & 41 & $63.4 \%$ & 50 & 54 & $92.6 \%$ & 76 & 95 & $80.0 \%$ \\
\hline 2. Food group detectives & 28 & 37 & $75.7 \%$ & 48 & 57 & $84.2 \%$ & 76 & 94 & $80.9 \%$ \\
\hline 3. Healthy choices & 13 & 39 & $33.3 \%$ & 40 & 43 & $93.0 \%$ & 53 & 82 & $64.6 \%$ \\
\hline 4. Get moving & 15 & 33 & $45.5 \%$ & 38 & 41 & $92.7 \%$ & 53 & 74 & $71.6 \%$ \\
\hline 5. Sun safety & 18 & 30 & $60.0 \%$ & 36 & 39 & $92.3 \%$ & 54 & 69 & $78.3 \%$ \\
\hline Total of all 5 lessons & 100 & 180 & $55.6 \%$ & 212 & 234 & $90.6 \%$ & 312 & 4147 & $5.4 \%$ \\
\hline
\end{tabular}

correct response to the knowledge questions ranging from $7 \%$ to $41 \%$ ( $p<0.0001$ for all 6 items). In comparison to first graders, the proportion of second graders correctly selecting the whole grain item, best post-exercise beverage, and length of time to exercise daily was significantly greater on the pre-curriculum survey. In addition, for the post-curriculum survey a significantly greater proportion of second graders correctly identified the appropriate length of time to exercise daily in comparison to first graders. Slightly more second graders correctly identified the sun safe hat in the post-curriculum survey $(p=0.09)$ compared to first graders. The question requiring students to correctly identify the sun safe hat showed the greatest increase in apparent understanding (41\%) with more than $92 \%$ of the students selecting the wide-brimmed hat on the post-test survey. The lowest change in proportion of students selecting the correct response was found in the question inquiring the best post-exercise beve- 
Table 2. Classroom teachers completed evaluation forms providing feedback on specific facets of the Healthy Children Arizona curriculum. The proportion of teachers rating the program components highly are provided.

\begin{tabular}{|c|c|c|c|c|c|}
\hline \multirow[b]{2}{*}{ Component being rated } & \multicolumn{5}{|c|}{ Lesson } \\
\hline & $\begin{array}{l}\text { 1. Rainbow on } \\
\text { my plate } \\
n=76\end{array}$ & $\begin{array}{l}\text { 2. Food group } \\
\text { detectives } \\
n=76\end{array}$ & $\begin{array}{l}\text { 3. Healthy } \\
\text { choices } \\
n=53\end{array}$ & $\begin{array}{l}\text { 4. Get } \\
\text { moving } \\
n=53\end{array}$ & $\begin{array}{l}\text { 5. Sun } \\
\text { safety } \\
n=54\end{array}$ \\
\hline & $\begin{array}{l}\text { \% good/very } \\
\text { good/excellent }\end{array}$ & $\begin{array}{l}\text { \% good/very good/ } \\
\text { excellent }\end{array}$ & $\begin{array}{l}\text { \% good/very good/ } \\
\text { excellent }\end{array}$ & $\begin{array}{l}\text { \% good/very } \\
\text { good/excellent }\end{array}$ & $\begin{array}{l}\text { \% good/very } \\
\text { good/excellent }\end{array}$ \\
\hline Quality of content & $100 \%$ & $100 \%$ & $98.0 \%$ & $100 \%$ & $100 \%$ \\
\hline Format/approach & $100 \%$ & $98.7 \%$ & $98.0 \%$ & $98.1 \%$ & $100 \%$ \\
\hline \multirow[t]{2}{*}{ Visual aids } & $100 \%$ & $100 \%$ & $100 \%$ & $100 \%$ & $100 \%$ \\
\hline & $\begin{array}{l}\text { \% very well/ } \\
\text { extremely well }\end{array}$ & $\begin{array}{l}\text { \% very well/ } \\
\text { extremely well }\end{array}$ & $\begin{array}{l}\text { \% very well/ } \\
\text { extremely well }\end{array}$ & $\begin{array}{l}\text { \% very well/ } \\
\text { extremely well }\end{array}$ & $\begin{array}{l}\text { \% very well/ } \\
\text { extremely well }\end{array}$ \\
\hline Linked to previously learned skills ${ }^{\mathrm{a}}$ & $69.1 \%$ & $86.7 \%$ & $94.2 \%$ & $94.1 \%$ & $91.7 \%$ \\
\hline Reflected lesson objectives & $77.3 \%$ & $82.7 \%$ & $80.8 \%$ & $92.3 \%$ & $92.6 \%$ \\
\hline Promotes healthy behaviors \& practices & $85.5 \%$ & $89.3 \%$ & $94.2 \%$ & $96.2 \%$ & $96.3 \%$ \\
\hline Provides for student feedback \& guidance & $80.0 \%$ & $82.4 \%$ & $88.5 \%$ & $90.2 \%$ & $92.2 \%$ \\
\hline Applies to students’ own lives ${ }^{\mathrm{a}}$ & $82.2 \%$ & $74.7 \%$ & $86.5 \%$ & $94.3 \%$ & $96.3 \%$ \\
\hline Motivates students to learn \& practice skills & $80.0 \%$ & $78.1 \%$ & $84.6 \%$ & $90.2 \%$ & $86.8 \%$ \\
\hline Was developmentally appropriate ${ }^{\mathrm{a}}$ & $81.6 \%$ & $79.1 \%$ & $84.3 \%$ & $96.2 \%$ & $85.2 \%$ \\
\hline $\begin{array}{l}\text { Was useful in assessing student application of } \\
\text { the lesson }{ }^{\mathrm{a}}\end{array}$ & $70.8 \%$ & $72.7 \%$ & $81.2 \%$ & $87.2 \%$ & $86.8 \%$ \\
\hline Adapts to student culltural differences & $64.8 \%$ & $54.6 \%$ & $68.6 \%$ & $70.0 \%$ & $75.9 \%$ \\
\hline $\begin{array}{l}\text { Averaged responses to } 9 \text { of the } \\
\text { lesson attributes }\end{array}$ & $76.8 \%$ & $77.8 \%$ & $84.8 \%$ & $90.1 \%$ & $89.3 \%$ \\
\hline
\end{tabular}

${ }^{\mathrm{a}}$ Proportion rating very well/extremely well differed by lesson, $\mathrm{p}=0.05$ or less.

Table 3. This table summarizes the students' responses to pre- and post-survey questions assessing understanding of the five Healthy Children Arizona lessons covering dietary, physical activity and sun safety information.

\begin{tabular}{|c|c|c|c|c|c|c|c|c|c|}
\hline \multirow[b]{2}{*}{ Survey question } & \multicolumn{2}{|c|}{ Pre-test } & \multicolumn{2}{|c|}{ Post-test } & \multicolumn{2}{|c|}{ Change } & \multicolumn{3}{|c|}{ All students } \\
\hline & 1st grade & 2nd grade & 1st grade & 2nd grade & 1st grade & 2nd grade & Pre-test & Post-test & Change \\
\hline $\begin{array}{l}\text { Which is a bone-building food? } \\
\text { circle picture of: grapes, carrot, milk, } \\
\text { fruit juice }\end{array}$ & $69.4 \%$ & $71.8 \%$ & $83.3 \%$ & $80.8 \%$ & $13.9 \%$ & $9.0 \%$ & $70.1 \%$ & $82.8 \%$ & $+12.7 \%^{\mathrm{a}}$ \\
\hline $\begin{array}{l}\text { Which food helps your brain } \\
\text { build muscle? circle picture of: egg, } \\
\text { apple, cookie, carrot }\end{array}$ & $11.6 \%$ & $10.3 \%$ & $24.3 \%$ & $26.9 \%$ & $12.7 \%$ & $16.6 \%^{\mathrm{b}}$ & $11.2 \%$ & $24.8 \%$ & $+13.6 \%^{\mathrm{a}}$ \\
\hline $\begin{array}{c}\text { Which is a whole grain choice? } \\
\text { circle picture of: whole wheat bread, } \\
\text { white bread }\end{array}$ & $52.1 \%$ & $69.2 \%{ }^{\mathrm{c}}$ & $79.1 \%$ & $75.0 \%$ & $27.0 \%$ & $5.8 \%$ & $56.6 \%$ & $78.4 \%$ & $+21.8 \%^{\mathrm{a}}$ \\
\hline $\begin{array}{l}\text { After you exercise, which is best to } \\
\text { drink? circle picture of: sports drink, } \\
\text { fruit juice, soda, water }\end{array}$ & $84.0 \%$ & $92.3 \%{ }^{\mathrm{d}}$ & $92.9 \%$ & $94.2 \%$ & $8.9 \%$ & $1.9 \%$ & $86.2 \%$ & $93.1 \%$ & $+6.9 \%{ }^{\mathrm{a}}$ \\
\hline $\begin{array}{l}\text { Which is the best hat to wear on a } \\
\text { sunny day? circle picture of: visor, } \\
\text { cap, wide-brimmed hat }\end{array}$ & $50.5 \%$ & $52.6 \%$ & $91.2 \%$ & $96.2 \%$ & $40.7 \%$ & $43.6 \%$ & $51.0 \%$ & $92.1 \%$ & $+41.1 \%^{\mathrm{a}}$ \\
\hline $\begin{array}{l}\text { How long should you exercise each } \\
\text { day? circle response: } 10 \text { minutes, } \\
15 \text { minutes, } 60 \text { minutes, } 120 \text { minutes }\end{array}$ & $27.8 \%$ & $41.0 \%{ }^{\mathrm{e}}$ & $58.6 \%$ & $73.1 \%{ }^{\mathrm{f}}$ & $30.8 \%$ & $32.1 \%$ & $31.3 \%$ & $61.2 \%$ & $+29.9 \%{ }^{\mathrm{a}}$ \\
\hline Mean\% correct of all questions & $49.2 \%$ & $56.2 \%$ & $71.6 \%$ & $74.4 \%$ & $22.4 \%$ & $18.2 \%$ & $51.1 \%$ & $72.1 \%$ & $21.0 \%^{\mathrm{a}}$ \\
\hline
\end{tabular}

${ }^{a}$ Pre-test to post-test there was a significant increase in the proportion of students answering the question correctly, p $<0.0001$. ${ }^{b}$ Pre-test to post-test there was a significant increase in the proportion of students answering the question correctly, $\mathrm{p}<0.0004$. ${ }^{\mathrm{C}}$ Proportion of correct responses differed by grade level, $\mathrm{p}=0.0002$. ${ }^{\mathrm{d}}$ Proportion of correct responses differed by grade level, $\mathrm{p}=0.01$. ${ }^{\mathrm{e}}$ Proportion of correct responses differed by grade level, $\mathrm{p}=$ 0.002. ${ }^{\mathrm{f}}$ Proportion of correct responses differed by grade level, $\mathrm{p}=0.006$. 
rage (correct response was water); however more than $86 \%$ of the children initially responded correctly to this question. Although the proportion of students who correctly selected the food item that helps the brain and builds muscle (egg) significantly increased, less than one-fourth of the children were able to select the appropriate response on the post-curriculum survey.

Figure 2 illustrates the change in the proportion of students reporting intake of zero, one, two, three, four, or five fruits and vegetables on the day previous to the survey. Initially, the distribution of fruit and vegetables eaten yesterday were significantly different by grade level $(p=0.04)$. Following the HCA curriculum, children reporting low servings of fruits and vegetables decreased, and there was a significant increase in the proportion of first, second, and all students reporting intake of five fruits and vegetables on the previous day $(p<0.0001, p=0.005$, and $\mathrm{p}<0.001$ for first, second, and all students, respectively). Table 4 summarizes the increase in mean selfreported fruit and vegetable intake reported by the children. There were no significant differences in mean intakes by grade level either pre or post curriculum, but the mean intake as reported by students of both grades significantly increased according to the post-curriculum survey.

\section{Discussion}

In 2010 the American Dietetic Association together with the School Nutrition Association and the Society for

\section{Student report of eating zero, one, two, three, four or five fruits and vegetables yesterday}

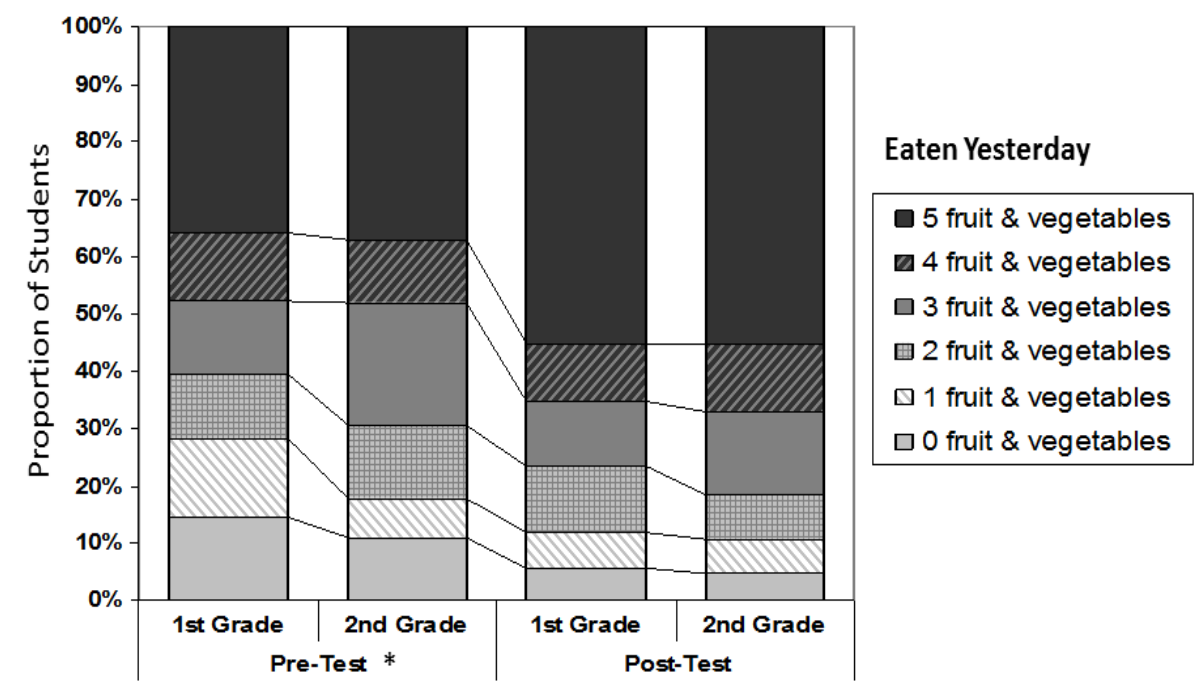

\footnotetext{
* Significant difference between 1st and 2nd graders pre-test reported distribution of fruit \& vegetable intake. $\mathrm{p}=0.04$
}

Figure 2. Student reporting of fruit and vegetable intake. Based on the pre-curriculum and post-curriculum surveys, this figure indicates the change in proportion of children reporting that yesterday he/she ate zero, one, two, three, four or five fruits and vegetables, by grade level.

Table 4. This table summarizes the mean number of fruit and vegetable servings eaten yesterday based on student response to the pre and post surveys.

\begin{tabular}{|c|c|c|c|}
\hline \multirow[b]{2}{*}{ Time point } & \multicolumn{3}{|c|}{ Servings of fruits and vegetables eaten yesterday } \\
\hline & $\begin{array}{c}\text { 1st Grade } \\
\text { mean + stddev }\end{array}$ & $\begin{array}{c}\text { 2nd Grade } \\
\text { mean + stddev }\end{array}$ & $\begin{array}{l}\text { All Students } \\
\text { mean + stddev }\end{array}$ \\
\hline Pre-test & $3.01+1.88$ & $3.26+1.71$ & $3.08+1.84$ \\
\hline Post-test & $3.79+1.88$ & $3.88+1.52$ & $3.81+1.59$ \\
\hline $\begin{array}{l}\mathrm{p} \text { value for significant } \\
\text { increase }\end{array}$ & $\mathrm{p}<0.0001$ & $\mathrm{p}=0.003$ & $\mathrm{p}<0.0001$ \\
\hline
\end{tabular}


Nutrition Education reaffirmed the commitment to provide nutrition education for school children. The position statement calls for comprehensive, integrated services in schools beginning in kindergarten [12]. Additionally, the passage and implementation of the Affordable Care Act is focusing attention on the physical and fiscal benefits of encouraging preventative health behaviors. The Healthy Children Arizona program helps to meet this call by effectively increasing student engagement in and knowledge of preventive health behaviors particularly in relation to food, physical activity and sun safety. Implementation of the five-lesson curriculum not only significantly increased knowledge of comprehensive healthy behaviors (including time recommended for daily activity and what constitutes a sun-safe hat), but also resulted in a significant increase in self-reported fruit and vegetable intake. Further, the process evaluation components suggest teachers are highly supportive of the curriculum and delivery within primary grade level classrooms.

Although a simple assessment instrument was used, examination of the pretest survey responses along with the teacher evaluation results indicate limited pre-curriculum knowledge about appropriate dietary, activity, or sun safety behaviors. The students could not correctly identify brain or muscle building foods or how many minutes to spend in physical activity daily. Only half of the students could identify a sun-safe hat and slightly more could select the whole grain item. Results from the teachers' initial evaluation likewise reinforces that the information being taught is new to the children and not currently included in the school curriculum. These elements indicate that the HCA curriculum is filling a significant gap in behavioral health curriculum.

Recent estimates suggest that more than 3.5 million skin cancers are treated annually in the United States and invasive melanoma rates continue to rise, although almost all cutaneous cancer is considered preventable with appropriate sun safe behaviors [13]-[15]. While Arizona leads the Nation in skin cancer incidence [16], it was also the first to mandate that skin cancer prevention be included in public school curriculum for kindergarten through eighth grades [17]. Along with early adoption of sun safe behaviors, a basic foundation in healthful dietary choices and a physically active lifestyle that includes daily moderate and vigorous activity provide the greatest potential to reduce the adult cancer burden. While the proportion of the American population that is overweight or obese has reached epidemic levels, the most striking increases and devastating effects may be among youth [2] [5] [18]. Overweight children are at greater risk of becoming obese as adults. Along with being at increased risk for several invasive cancer types such as colorectal, breast, and endometrial, overweight/obese adults are at greater risk for cardiovascular disease and consequently premature death [2] [19].

\subsection{Role of School-Based Education}

During the school year, almost one-third of a child's non-sleeping time is spent at school. Schools strengthen neighborhoods and provide access to a core of information that allows each generation to contribute and further the community. Healthier children are better prepared and receptive to the learning environment; the inclusion of strategies to optimize health and facilitate learning is appropriate [8] [11] [20]-[24]. Early experiences, including those in the classroom setting, influence attitudes and acceptability, key issues in behavioral choices particularly in relation to a child's willingness to try new experiences. A substantial body of literature attests to the effectiveness and efficiency of administering school-based programs to intervene for public health concerns that are amenable to behavior change [8] [11] [20] [21] [23] [24].

\subsection{Comparison of Results to Other Programs}

Increasing fruit and vegetable intake is one component of HCA and a common aim in several school-based interventions. Wang and colleagues reported a significant one-half serving increase in fruit and vegetable intake among fourth and fifth graders using a program that included nutrition education, gardening and cooking [25]. The St. Paul, Minnesota "5-a-day Power Plus" program targeted a multiethnic population of fourth grades among 20 elementary schools [26]. The program used a much different approach than the curriculum-based intervention tested here and included school cafeteria changes, parent sessions and industry support to result in an increase in lunchtime and daily fruit intake among all children and vegetable intake among girls as assessed by 24-hour recall and lunchtime observational measurements. The high-5 program in Alabama was one of a few programs developed to increase fruit and vegetable intake for cancer risk reduction consistent with the objectives of the HCA program. Approximately 1700 families were involved in the program. Mean daily fruit and vegetable intake were significantly increased over baseline among the elementary school children at the end of 
year one and year two [27] [28]. Several reviews and meta-analysis of current evidence suggest that educational interventions can significantly increase fruit and vegetable intakes among children including those aged six to twelve years [29]-[31]. Along with fruit and vegetable intake, HCA encourages recognition and consumption of whole grain foods. A multi-component intervention by Burgess-Champoux and colleagues has previously demonstrated that children can learn to readily identify, and consume whole grain foods, and schools can successfully increase the availability of whole grain items [32].

HCA is not the only program to include both dietary and physical activity aims. IMPACT—Improving Meals and Physical Activity in Children recruited and trained high school students to deliver a program to improve nutrition and physical activity in fourth graders. The small intervention study lead to a significant improvement of 0.85 fruit and vegetable servings per day among the fourth grader and non-significant improvements in intake among the high school students [33]. The CATCH Kids Club (CKC) targeted improvements in nutrition and physical activity by training after-school staff to lead activity and deliver educational curriculum. While the activity sessions were well received, the authors noted that the Austin and El Paso children did not respond well to the educational curricula delivery in the after-school setting. Additionally, the authors noted routine staff training was necessary and there was high turnover in after-school staffing.

One unique yet important aspect of the HCA program is the inclusion of sun safety curricula in conjunction with encouraging recommended levels of physical activity and healthful diet choices. The US Environmental Protection Agency provides schools with the SunWise ${ }^{\mathrm{TM}}$ curricula validated to ensure that the brief instruction on sun safety can be successfully interwoven across core curricula to significantly improve understanding and behavior intentions among kindergarten through eighth graders [15] [34].

\subsection{Strengths and Limitations}

HCA is a comprehensive, behavior-based classroom curriculum designed to improve young children’s understanding of healthful eating, physical activity needs and sun safety. This preliminary evaluation suggests the program can be effectively delivered, is well received by teachers and results in significant healthy lifestyle behavior change among 1st and 2nd graders. Importantly, the HCA program objectives are based on state requirements and fulfill multiple educational standards for state core curricula. The HCA curriculum also is successful across a diverse and sizable student population in two distinct metropolitan areas further supporting the ease with which the curricula can be disseminated. Since the HCA curriculum was delivered by professionals external to the schools, the availability of trained external delivery personnel does increase cost. Due to the student survey administration timing, no kindergarten children were represented in the assessment population although this age group is included in the HCA target population. Because the survey did not contain personal identifiers, matching of pre and post curricula responses for individual students was not possible. Although significant improvement in understanding was realized for each of the six measured concepts, the proportion of student correctly recognizing brain and muscle building foods, selecting the whole grain food item, and choosing the correct amount of time for physical activity daily were less than ideal. Our findings afford an opportunity to improve on the current HC curriculum in order to reinforce these important concepts.

\section{Conclusion}

The young children exposed to the Healthy Children Arizona curricula demonstrated significant improvement in understanding of six prevention concepts covering dietary, physical activity and sun safety behaviors. Establishing prevention behaviors early in life may be critical to reversing the current trends of increasing prevalence of chronic disease, including cancer. With innovative treatments available, most invasive cancers are survivable. However $40 \%$ of all invasive cancers and almost all skin cancers could be prevented through lifestyle choices leading to substantial reductions in personal disease burden and healthcare costs. The ideal approach to minimizing the burden of cancer is to prevent cancer incidence. The comprehensive Healthy Children Arizona program successfully introduces young children to the important cancer prevention concepts needed to establish cancer-preventive benefit in later life.

\section{Acknowledgements}

We greatly appreciate the extra time and effort of the participating teachers in providing feedback. 


\section{References}

[1] Wiseman, M. (2008) The Second World Cancer Research Fund/American Institute for Cancer Research Expert Report. Food, Nutrition, Physical Activity, and the Prevention of Cancer: A Global Perspective. Proceedings of the Nutrition Society, 67, 253-256. http://dx.doi.org/10.1017/S002966510800712X

[2] Trust for America's Health (TFAH) and the Robert Wood Johnson Foundation (RWJF) (2010) F as in Fat: How Obesity Threatens America’s Future. http://www.healthyamericans.org/reports/obesity2010

[3] Ogden, C.L., Carroll, M.D., Curtin, L.R., Lamb, M.M. and Flegal, K.M. (2010) Prevalence of High Body Mass Index in US Children and Adolescents, 2007-2008. JAMA, 303, 242-249. http://dx.doi.org/10.1001/jama.2009.2012

[4] Thompson, R. (2010) Preventing Cancer: The Role of Food, Nutrition and Physical Activity. Journal of Family Health Care, 20, 100-102.

[5] Child and Adolescent Health Measurement Initiative (2007) 2007 National Survey of Children’s Health. http://www.childhealthdata.org

[6] Singh, G.K., Kogan, M.D. and Van Dyck, P.C. (2010) Changes in State-Specific Childhood Obesity and Overweight Prevalence in the United States from 2003 to 2007. Archives of Pediatrics and Adolescent Medicine, 164, 598-607.

[7] (2009) Obesity Prevalence among Low-Income, Preschool-Aged Children-United States, 1998-2008. MMWR Morbidity and Mortality Weekly Report, 58, 769-773.

[8] Zylke, J.W. and De Angelis, C.D. (2009) Health Promotion and Disease Prevention in Children: It’s Never Too Early. JAMA, 301, 2270-2271.

[9] Baranowski, T., Davis, M., Resnicow, K., Baranowski, J., Doyle, C., Lin, L.S., et al. (2000) Gimme 5 Fruit, Juice, and Vegetables for Fun and Health: Outcome Evaluation. Health Education Behavior, 27, 96-111. http://dx.doi.org/10.1177/109019810002700109

[10] National Cancer Institute (NIH) (2005) Theory at a Glance-A Guide for Health Promotion Practice. NIH Publication No. 05-3896 [Second], National Cancer Institute, National Institutes of Health, Washington DC.

[11] Perez-Rodrigo, C. and Aranceta, J. (2003) Nutrition Education in Schools: Experiences and Challenges. European Journal of Clinical Nutrition, 57, S82-S85. http://dx.doi.org/10.1038/sj.ejcn.1601824

[12] Briggs, M., Fleischhacker, S. and Mueller, C.G. (2010) Position of the American Dietetic Association, School Nutrition Association, and Society for Nutrition Education: Comprehensive School Nutrition Services. Journal of Nutrition Education and Behavior, 42, 360-371. http://dx.doi.org/10.1016/j.jneb.2010.08.007

[13] Chen, J.G., Fleischer Jr., A.B., Smith, E.D., Kancler, C., Goldman, N.D., Williford, P.M. and Feldman, S.R. (2001) Cost of Nonmelanoma Skin Cancer Treatment in the United States. Dermatologic Surgery, 27, 1035-1038. http://dx.doi.org/10.1046/j.1524-4725.2001.01004.x

[14] Geller, A.C., Rutsch, L., Kenausis, K., Selzer, P. and Zhang, Z. (2003) Can an Hour or Two of Sun Protection Education Keep the Sunburn Away? Evaluation of the Environmental Protection Agency’s Sunwise School Program. Environmental Health, 2, 13-19. http://dx.doi.org/10.1186/1476-069X-2-13

[15] Rogers, H.W., Weinstock, M.A., Harris, A.R., Hinckley, M.R., Feldman, S.R., Fleischer, A.B. and Coldiron, B.M. (2010) Incidence Estimate of Nonmelanoma Skin Cancer in the United States, 2006. JAMA Dermatology, 146, 283287. http://dx.doi.org/10.1001/archdermatol.2010.19

[16] Harris, R.B., Griffith, K. and Moon, T.E. (2001) Trends in the Incidence of Nonmelanoma Skin Cancers in Southeastern Arizona, 1985-1996. Journal of the American Academy of Dermatology, 45, 528-536. http://dx.doi.org/10.1067/mjd.2001.114742

[17] State of Arizona Legislature (2005) Instruction on Skin Cancer Prevention. ARS 15-718, Chapter 7, Article 1 (Curriculum).

[18] Abrams, P. and Levitt Katz, L.E. (2011) Metabolic Effects of Obesity Causing Disease in Childhood. Current Opinion in Endocrinology, Diabetes \& Obesity, 18, 23-27. http://dx.doi.org/10.1097/MED.0b013e3283424b37

[19] Story, M., Kaphingst, K.M. and French, S. (2006) The Role of Schools in Obesity Prevention. Future of Children, 16, 109-142. http://dx.doi.org/10.1353/foc.2006.0007

[20] Pateman, B., Irvin, L.H., Shoji, L. and Serna, K. (2004) Building School Health Programs through Public Health Initiatives: The First Three Years of the Healthy Hawaii Initiative Partnership for School Health. Preventing Chronic Disease, 1, A10.

[21] Perez-Rodrigo, C. and Aranceta, J. (2001) School-Based Nutrition Education: Lessons Learned and New Perspectives. Public Health Nutrition, 4, 131-139. http://dx.doi.org/10.1079/PHN2000108

[22] Ritchie, A. (2001) Nutrition Education and Promotion in Primary Schools. Australian Journal of Holistic Nursing, 8, 39-44. 
[23] Schneider, M., Hall, W.J., Hernandez, A.E., Hindes, K., Montez, G., Pham, T., et al. (2009) Rationale, Design and Methods for Process Evaluation in the HEALTHY Study. International Journal of Obesity, 33, S60-S67. http://dx.doi.org/10.1038/ijo.2009.118

[24] Shaya, F.T., Flores, D., Gbarayor, C.M. and Wang, J.S. (2008) School-Based Obesity Interventions: A Literature Review. Journal of School Health, 78, 189-196. http://dx.doi.org/10.1111/j.1746-1561.2008.00285.x

[25] Wang, M.C., Rauzon, S., Studer, N., Martin, A.C., Craig, L., Merlo, C., et al. (2010) Exposure to a Comprehensive School Intervention Increases Vegetable Consumption. Journal of Adolescent Health, 47, 74-82. http://dx.doi.org/10.1016/j.jadohealth.2009.12.014

[26] Perry, C.L., Bishop, D.B., Taylor, G., Murray, D.M., Mays, R.W., Dudovitz, B.S., et al. (1998) Changing Fruit and Vegetable Consumption among Children: The 5-a-Day Power Plus Program in St. Paul, Minnesota. American Journal of Public Health, 88, 603-609. http://dx.doi.org/10.2105/AJPH.88.4.603

[27] Reynolds, K.D., Franklin, F.A., Leviton, L.C., Maloy, J., Harrington, K.F., Yaroch, A.L., et al. (2000) Methods, Results, and Lessons Learned From Process Evaluation of the High 5 School-Based Nutrition Intervention. Health Education \& Behavior, 27, 177-186. http://dx.doi.org/10.1177/109019810002700204

[28] Reynolds, K.D., Franklin, F.A., Binkley, D., Raczynski, J.M., Harrington, K.F., Kirk, K.A. and Person, S. (2000) Increasing the Fruit and Vegetable Consumption of Fourth-Graders: Results from the High 5 Project. Preventive Medicine, 30, 309-319. http://dx.doi.org/10.1006/pmed.1999.0630

[29] Van Cauwenberghe, E., Maes, L., Spittaels, H., Van Lenthe, F.J., Brug, J., Oppert, J.M. and De Bourdeaudhuij, I. (2010) Effectiveness of School-Based Interventions in Europe to Promote Healthy Nutrition in Children and Adolescents: Systematic Review of Published and “Grey” Literature. British Journal of Nutrition, 103, 781-797. http://dx.doi.org/10.1017/S0007114509993370

[30] Howerton, M.W., Bell, B.S., Dodd, K.W., Berrigan, D., Stolzenberg-Solomon, R. and Nebeling, L. (2007) SchoolBased Nutrition Programs Produced a Moderate Increase in Fruit and Vegetable Consumption: Meta and Pooling Analyses from 7 Studies. Journal of Nutrition Education and Behavior, 39, 186-196. http://dx.doi.org/10.1016/j.jneb.2007.01.010

[31] McArthur, D.B. (1998) Heart Healthy Eating Behaviors of Children Following a School-Based Intervention: A MetaAnalysis. Issues in Comprehensive Pediatric Nursing, 21, 35-48. http://dx.doi.org/10.1080/01460869808951126

[32] Burgess-Champoux, T.L., Chan, H.W., Rosen, R., Marquart, L. and Reicks, M. (2008) Healthy Whole-Grain Choices for Children and Parents: A Multi-Component School-Based Pilot Intervention. Public Health Nutrition, 11, 849-859. http://dx.doi.org/10.1017/S1368980007001346

[33] Muth, N.D., Chatterjee, A., Williams, D., Cross, A. and Flower, K. (2008) Making an IMPACT: Effect of a SchoolBased Pilot Intervention. North Carolina Medical Journal, 69, 432-440.

[34] Geller, A., Rutsch, L., Kenausis, K. and Zhang, Z. (2003) Evaluation of the Sun Wise School Program. Journal of School Nursing, 19, 93-99. http://dx.doi.org/10.1177/10598405030190020601 
Scientific Research Publishing (SCIRP) is one of the largest Open Access journal publishers. It is currently publishing more than 200 open access, online, peer-reviewed journals covering a wide range of academic disciplines. SCIRP serves the worldwide academic communities and contributes to the progress and application of science with its publication.

Other selected journals from SCIRP are listed as below. Submit your manuscript to us via either submit@scirp.org or Online Submission Portal.
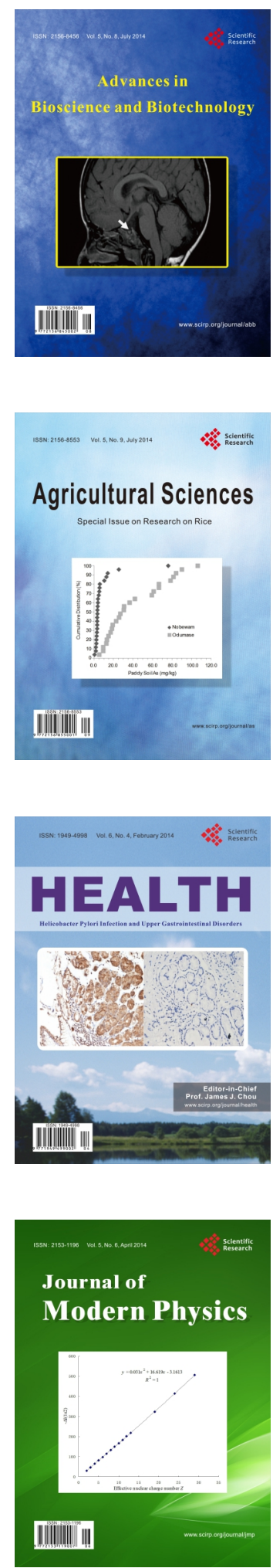
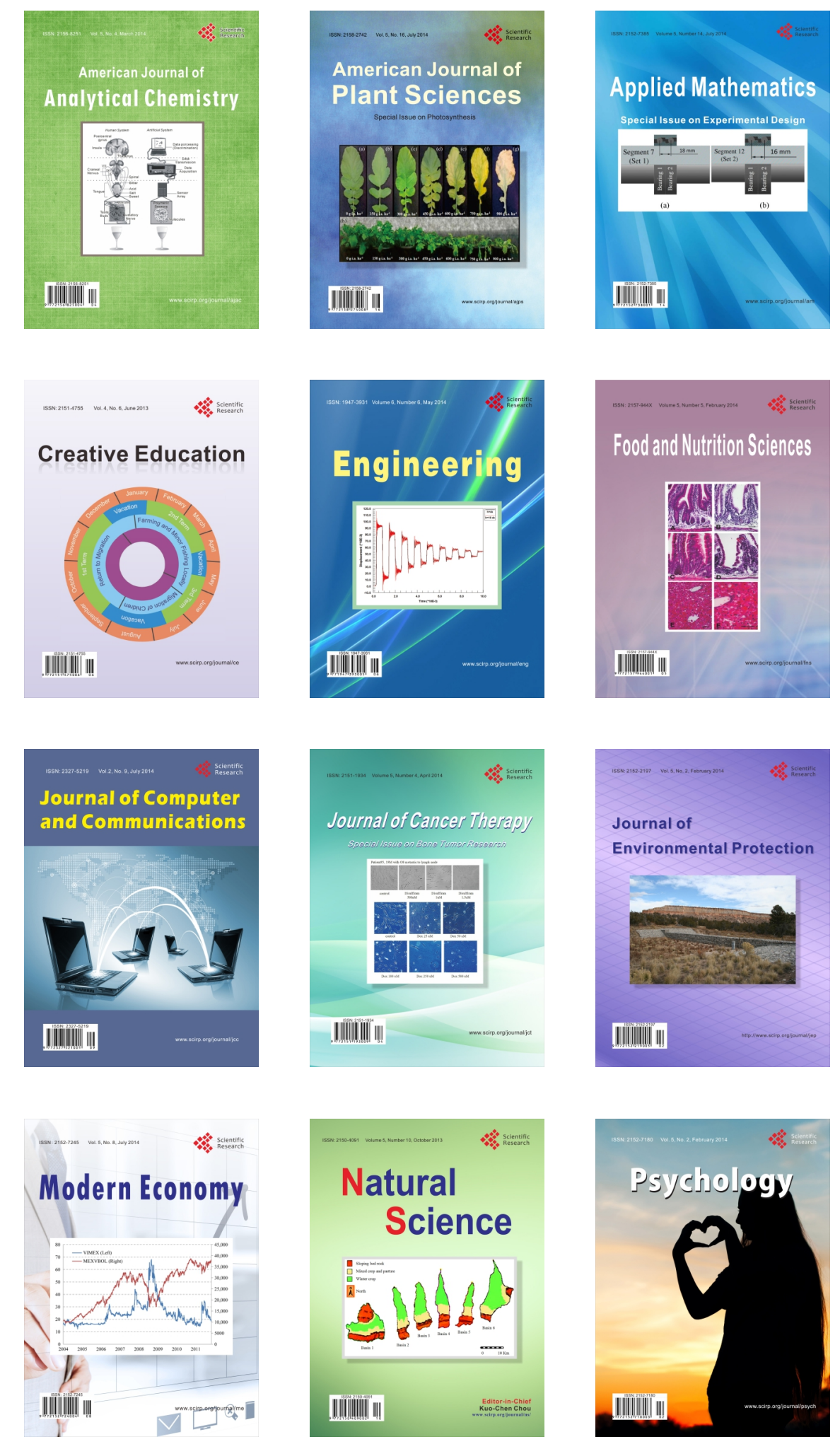